\title{
Efeito de formulações cúpricas e cuprorgânicas na severidade da man- cha-bacteriana e na população residente de Xanthomonas campestris pv. vesicatoria em pimentão ${ }^{1}$
}

\author{
Luiz Augusto de Aguiar; Osamu Kimura( $\dagger$; ; Alzimiro Marcelo C. Castilho; Kátia Simone C. Castilho; \\ Raul de Lucena D. Ribeiro; Fujio Akiba; Margarida Goréte F. do Carmo \\ UFRRJ, BR 465, Km. 7 (Antiga Rodovia Rio-São Paulo, Km. 47), 23851-970 Seropédica-RJ; E-mail: luizaguiar@domain.com.br; \\ gorete@ufrrj.br
}

\section{RESUMO}

Foram conduzidos dois experimentos de campo, em locais isolados entre si, objetivando avaliar o efeito de formulações cúpricas e cuprorgânicas na redução de populações de Xanthomonas campestris $p v$. vesicatoria presentes no filoplano do pimentão, bem como na redução da severidade dos sintomas da mancha-bacteriana. Numa das áreas experimentais, plantas da cultivar Cascadura Itaipu foram inoculadas com o isolado ENA-818, sensível ao cobre; na outra área, plantas da mesma cultivar foram inoculadas com o isolado ENA-4369, resistente a $900 \mu \mathrm{g} / \mathrm{ml} \mathrm{de} \mathrm{Cu}^{++}$in vitro. Em ambas as áreas, os cultivos foram pulverizados semanalmente com diferentes produtos químicos (sulfato de cobre, oxicloreto de cobre, óxido cuproso e óxido cuproso+mancozeb), incluindo-se um tratamento testemunha constituído de parcelas pulverizadas com água bidestilada e deionizada. Avaliações procedidas durante o ciclo das culturas demonstraram que somente o óxido cuproso e sua mistura com mancozeb foram capazes de reduzir, significativamente, os níveis de população residente dos isolados. Entretanto, todos os tratamentos químicos diferiram da testemunha quanto à redução de área foliar útil pela bactéria, medida através da "Área Abaixo da Curva de Progresso da Doença" (AACPD), na cultura inoculada com a cepa ENA818. Por outro lado, no campo experimental inoculado com o isolado ENA-4369 (resistente ao cobre), os tratamentos não diferiram da testemunha nesse particular, indicando que as concentrações de $\mathrm{Cu}^{++}$ nos produtos utilizados foram insuficientes para promover controle satisfatório após o estabelecimento da doença.

Palavras-chave: Capsicum annuum, epidemiologia, fitobactéria, resistência ao cobre.

\begin{abstract}
Effect of copper formulations on resident Xanthomonas campestris $p v$. vesicatoria populations on sweet pepper leaf surfaces

Two isolated field experiments were carried out to evaluate the effect of copper and copper+carbamate formulations on resident Xanthomonas campestris pv. vesicatoria populations on sweet pepper leaf surfaces, as well as on symptom severity of bacterial spot. In one of the fields, plants of cv. Cascadura Itaipu were inoculated with isolate ENA-818 showing copper sensibility; in the second field the same cultivar was inoculated with isolate ENA-4369 resistant or tolerant up to $900 \mu \mathrm{g} / \mathrm{ml}$ of $\mathrm{Cu}^{++}$in vitro. In both areas the crops were weekly sprayed with different chemical compounds (copper sulphate, copper oxichloride, cuprous oxide and cuprous oxide+mancozeb) including a control treatment sprayed with distilled/deinonized water. Evaluations carried out during the crop cycle showed that only cuprous oxide and its mixture with mancozeb were able to reduce bacterial population levels. However all chemical treatments differed from the control treatment as related to reduction of functional leaf area estimated by the "Area Under Disease Progress Curve" in the field inoculated with ENA-818. On the other hand, in the field inoculated with ENA-4369 (resistant to copper) the chemical treatments did not differ from the control, indicating that $\mathrm{Cu}^{++}$ concentrations of the products were not sufficient to promote a satisfactory reduction of bacterial spot severity and epiphytic $X$. $c$. $p v$. vesicatoria population after disease onset.
\end{abstract}

Keywords: epidemiology, bacterial spot, Capsicum annuum, copper resistance.

\section{(Recebido para publicação em 17 de agosto de 2001 e aceito em 20 de dezembro de 2002)}

$\mathrm{O}$ pimentão é uma das hortaliças mais importantes economicamente no Brasil, com especial destaque para o estado do Rio de Janeiro. Sua alta produtividade muitas vezes é reduzida pela ocorrência de várias doenças, particularmente as bacterioses. Dentre estas destaca-se a pústula-bacteriana ou manchabacteriana, causada por Xanthomonas campestris pv. vesicatoria (Doidge) Dye (Kimura \& Carmo, 1996). Esta bactéria foi reclassificada, recentemente, propondo-se duas novas espécies: Xanthomonas vesicatoria e Xanthomonas axonopodis pv. vesicatoria (Jones et al., 1998). A manchabacteriana ocorre em praticamente todas as regiões produtoras dessa hortaliça no Brasil, representando fator de prejuízo significante (Kimura, 1984). Devido à inexistência de cultivares resistentes, essa bacteriose pode ocasionar danos ainda mais sérios quando a cultura é conduzida sob condições de chuvas prolongadas e temperaturas entre 22 e $32^{\circ} \mathrm{C}$ (Kimura \& Carmo, 1996). O êxito ou fracasso do controle químico à bactéria pode ser, em parte, atribuído à maior ou menor eficácia dos princípios ativos aplicados, a cuidados e épocas de tratamento e, principalmente, à sensibilidade ou resistência das populações do patógeno a bactericidas comumente empregados (Stall, 1993; Kimura \& Carmo, 1996).

\footnotetext{
${ }^{1}$ Parte da dissertação de mestrado apresentada pelo primeiro autor ao curso de pós-graduação em fitotecnia, da UFRRJ; trabalho parcialmente financiado pela coordenadoria de aperfeiçoamento de pessoal do ensino superior (CAPES)
} 
Populações de bactérias residentes ou epífitas podem constituir inóculo capaz de iniciar epidemias, quando as condições de ambiente tornam-se favoráveis à infecção (Hirano \& Upper, 1990). Podem também sobreviver na superfície de tecidos verdes de ervas espontâneas e de plantas cultivadas nãohospedeiras (Hirano \& Upper, 1990). Carmo et al. (1996) consideraram ser a população residente de $X$. campestris pv. vesicatoria $(X c v)$ um dos fatores responsáveis pelo rápido aumento das taxas de infecção a partir da ocorrência de ambiente propício a epidemias da mancha-bacteriana do pimentão. Bashan et al. (1982) verificaram a sobrevivência como residente de $X c v$ em folhas de pimentão, que somente apresentaram sintomas da mancha-bacteriana quando as condições climáticas se tornaram favoráveis. Kimura et al. (1981) correlacionaram níveis de populações residentes de $X c v$ à maior ou menor suscetibilidade de linhagens de Capsicum annuum, assim evidenciando que substâncias porventura presentes na superfície das folhas poderiam exercer influência na multiplicação da bactéria.

Para otimizar o controle a fitobactérias deve-se recorrer, sempre que possível, a cultivares resistentes, redução do inóculo inicial, práticas de manejo que tornem o ambiente menos favorável, adicionados do uso de agroquímicos, que sob manejo incorreto pode encarecer os custos de produção, intensificar a pressão de seleção de populações bacterianas resistentes, tornando-os ineficazes (Marco \& Stall, 1983; Adaskaveg \& Hine, 1985; Maringoni \& Kimati, 1987).

Nos EUA e no México têm sido obtidos isolados de $X c v$ resistentes a fungicidas cúpricos, correlacionando-se sua ocorrência natural à redução da eficácia desses tratamentos (Marco \& Stall, 1983; Adaskaveg \& Hine, 1985). A exemplo dos estados da Florida, Oklahoma e Georgia nos EUA (Gitaitis et al., 1985; Canteros et al., 1990), e de outras regiões como Taiwan e Argentina (Canteros et al., 1990), também no Brasil foi registrada a ocorrência de populações de $X c v$ resistentes ao cobre (Maringoni \& Kimati, 1987; Aguiar et al., 2000). Aguiar et al. (2000) consta- taram, tanto em cultivos de pimentão como de tomate, isolados da bactéria resistentes desde 28 até $1800 \mathrm{mg} / \mathrm{ml}$ de $\mathrm{Cu}^{++}$in vitro em vários municípios do estado do Rio de Janeiro. Marco \& Stall (1983) e Maringoni \& Kimati (1987) relataram que isolados de $X c v$ resistentes ao cobre eram sensíveis à mistura de cobre com etilenobisditiocarbamatos (mancozeb ou zineb), tanto in vitro quanto aplicados às plantas. Maringoni \& Kimati (1987) observaram que misturas de fungicidas cúpricos (hidróxido de cobre, oxicloreto de cobre e óxido cuproso) com etilenobisditiocarbamatos (maneb, mancozeb e zineb) apresentavam efeito sinergístico, sendo requeridas concentrações mais baixas dos cúpricos para inibir a bactéria. McCarter (1992) conseguiu, através de pulverizações semanais de hidróxido de cobre + mancozeb, controle satisfatório do agente da mancha-bacteriana em pimentão, com incrementos em produtividade da ordem de $76 \%, 117 \%$ e $83 \%$, nas safras de 1987, 1988 e 1989, respectivamente. Carmo et al (2001), no entanto, observaram em cinco ensaios eficiência variável do controle da mancha-bacteriana do pimentão com oxicloreto de cobre e nenhuma relação, a princípio, com a seleção de isolados sensíveis ao cobre.

Tendo em vista as constantes perdas causadas pela mancha-bacteriana do pimentão, à variação na eficiência de seu controle com formulações à base de cobre e ao relato da ocorrência de estirpes de $X c v$ resistentes ao cobre no estado do Rio de Janeiro, foi idealizado o presente trabalho, tendo como objetivos avaliar, em condições de campo, em epidemias desenvolvidas a partir de isolados resistente e sensível ao cobre: 1) o efeito de diferentes formulações à base de cobre sobre a população residente da bactéria em plantas de pimentão; 2) a eficiência destes no controle da doença; 3) a correlação entre a dinâmica da população residente e a severidade da doença, sob manejo com fungicidas cúpricos.

\section{MATERIAL E MÉTODOS}

Foram conduzidos entre 11/93 e 02/

94, dois ensaios de campo em
Seropédica (RJ). Um desses ensaios foi implantado na Área de Fitopatologia (AF) e o outro no Campo Experimental (CE), ambos da UFRRJ, afastados entre si por cerca de $300 \mathrm{~m}$ e isolados por dois prédios e abundante vegetação. Em cada um dos ensaios, empregou-se a cultivar de pimentão Cascadura Itaipu, suscetível à mancha-bacteriana e os isolados de $X c v$ de pimentão ENA-4369 (AF) e ENA-818 (CE), que haviam mostrado resistência a até $900 \mathrm{mg} / \mathrm{ml} \mathrm{e}$ $3,5 \mu \mathrm{g} / \mathrm{ml}$ de cobre in vitro, respectivamente (Aguiar et al., 2000).

Mudas produzidas em bandejas de poliestireno expandido de 128 células em casa-de-vegetação foram selecionadas e transferidas para copos de plástico de $300 \mathrm{ml}$ contendo substrato à base de subsolo argiloso, areia, esterco bovino curtido e composto orgânico mais $1,0 \mathrm{~kg}$ da formulação NPK (4:14:8) por 100 litros da mistura. As mudas foram mantidas sob telado (sombrite com $50 \%$ de redução de luz solar) até atingirem cerca de $20 \mathrm{~cm}$ de altura, ocasião em que foram transplantadas para os locais definitivos, no espaçamento de $1,0 \times 0,5 \mathrm{~m}$. Seguiram-se tratos culturais regulares, com capinas manuais e adubações de cobertura e irrigação por aspersão.

Os inóculos dos isolados ENA-4369 e ENA-818 foram obtidos a partir de culturas puras com $48 \mathrm{~h}$ de crescimento, a $28+2^{\circ} \mathrm{C}$, em meio de Dygs (Rodrigues Neto et al., 1986) e as inoculações feitas com auxílio de um multinoculador de seis agulhas, previamente embebidas em suspensão bacteriana contendo cerca de $10^{6}$ ufc/ml, por meio de perfurações de duas folhas situadas no terço apical de dez plantas por parcela, situadas na fileira central. Após as inoculações, seguiramse irrigações diárias até aparecimento dos sintomas.

As inoculações foram efetuadas em 28/11/93, 30 dias após o transplante, início do florescimento, e as pulverizações iniciaram-se 16 dias após, com a constatação dos primeiros sintomas da doença. Seguiram-se pulverizações semanais, durante 60 dias, totalizando nove aplicações.

Compararam-se quatro formulações distintas, obtidas de produtos comerciais diluídos em água bidestilada e 
deionizada, com o tratamento testemunha (água bidestilada e deionizada). As dosagens de cobre $\left(\mathrm{Cu}^{++}\right)$variaram nessas formulações, seguindo-se as recomendações dos respectivos fabricantes, a saber: 1) $0,44 \mathrm{~g} / \mathrm{l}$ de sulfato de cobre $\left.\left(\mathrm{CuSO}_{4} .5 \mathrm{H}_{2} \mathrm{O}\right) ; 2\right) 2,10 \mathrm{~g} / \mathrm{l}$ de oxicloreto de cobre; 3) 1,12 g/l de óxido cuproso; 4) $1,12 \mathrm{~g} / \mathrm{l}$ de óxido cuproso+0,80 g/l de mancozeb. As concentrações de cobre nos produtos originais (anteriormente à suspensão em água) foram determinadas através de espectrofotometria de absorção atômica, com os seguintes ajustes: comprimento de onda de 324,8 $\mathrm{hm}$, corrente da lâmpada de $3 \mathrm{~mA}$, fenda de $100 \mathrm{~mm}$ e chama oxidante de $\mathrm{Ar} /$ $\mathrm{C}_{2} \mathrm{H}_{2}$. Essas concentrações corresponderam a valores de sulfato de cobre $=112,5 \mu \mathrm{g} / \mathrm{ml}$; oxicloreto de cobre $=42,6 \mu \mathrm{g} / \mathrm{ml}$; óxido cuproso $=20,2$ $\mu \mathrm{g} / \mathrm{ml}$ e óxido cuproso+mancozeb $=$ $22,2 \mu \mathrm{g} / \mathrm{ml}$.

Os volumes de calda utilizados variaram de acordo com o necessário ao completo molhamento da parte aérea das plantas. A mistura cuprorgânica foi aplicada $6 \mathrm{~h}$ após o seu preparo.

$\mathrm{O}$ delineamento experimental utilizado nos dois ensaios foi o de blocos ao acaso com cinco tratamentos e três repetições. Cada parcela correspondeu a quatro fileiras de nove plantas, sendo a área útil constituída por 10 plantas situadas nas duas fileiras internas. Os blocos ficaram separados entre si por uma distância de 2 m e continham 164 plantas, perfazendo o total de 492 plantas em cada campo experimental.

O monitoramento das populações residentes de $X c v$ iniciou-se três dias após a primeira pulverização, em 16 e 17/12/93, nos respectivos ensaios, e prosseguiu, semanalmente, durante todo o desenvolvimento da cultura, totalizando oito avaliações. Em cada avaliação retirou-se ao acaso uma folha/ planta da brotação de cinco indivíduos na área útil de cada parcela. As amostras foram sempre compostas de folhas sem sintomas macroscópicos da mancha-bacteriana e com largura máxima superior a $2 \mathrm{~cm}$. Logo após a coleta as folhas foram acondicionadas em sacos de polietileno sem uso prévio e levadas ao laboratório. Em seguida, foram retirados 10 discos foliares de 1,3 $\mathrm{cm}^{2}$ (dois discos/folha), com auxílio de furador-de-rolha ("saca-bocado"). Imediatamente após, os discos foram colocados em frascos de Erlenmeyer de 250 $\mathrm{ml}$, contendo $20 \mathrm{ml}$ de solução extratora esterilizada. Essa solução era constituída de: $5,3 \mathrm{~g}$ de $\mathrm{KH}_{2} \mathrm{PO}_{4}, 8,6 \mathrm{~g}$ de $\mathrm{Na}_{2} \mathrm{HPo}_{4}, \quad 1,0 \quad \mathrm{~g}$ de peptona bacteriológica por litro de água bidestilada e deionizada, a pH 7,0. Os frascos, correspondentes a cada parcela, foram então agitados por 30 minutos em "shaker" regulado para 150 oscilações por minuto. Após esse período de agitação, alíquotas de $0,5 \mathrm{ml}$ foram pipetadas e submetidas a quatro diluições seriadas de $1 / 10$ em tampão fosfato a $0,005 \mathrm{M}$ (pH 7,0), contendo $0,85 \%$ de $\mathrm{NaCl}$. Dessas diluições, novas alíquotas de $0,1 \mathrm{ml}$ foram distribuídas uniformemente na superfície de três placas de Petri contendo meio de Dygs. Após quatro dias de incubação a $28+2^{\circ} \mathrm{C}$, as placas foram avaliadas com referência ao número de colônias típicas de $X c v$. Os resultados obtidos nas contagens representaram o número de unidades formadoras de colônias por $\mathrm{cm}^{2}$ de limbo foliar ( $\mathrm{ufc} / \mathrm{cm}^{2}$ ), cujos valores foram transformados em log ufc/ $\mathrm{cm}^{2}$. De posse destes dados, construíram-se curvas representando a evolução da população residente da bactéria ao longo do período de avaliação. Calcularam-se, ainda, os valores relativos à "Área Abaixo da Curva de Progresso da População Residente (AACPPR) (Carmo et al., 1996), os quais foram submetidos à análise de variância e separação das médias pelo teste de Duncan a 5\% de probabilidade.

A quantificação da intensidade da mancha-bacteriana iniciou-se 60 dias após o transplante e 14 dias após a primeira pulverização, seguindo-se sete avaliações semanais, até o final do ensaio. A severidade foi estimada com auxílio da escala de Horsfall \& Barrat (1945) computando-se tanto área foliar lesionada como a perda de área foliar resultante da abscisão prematura. Para efeito de análise consideraram-se os dados expressos em proporção, variando de 0 a 1.

Após tabulação dos dados de severidade, calcularam-se os valores da área abaixo da curva de progresso da doença (AACPD) (Carmo et al., 1996). Os va- lores de AACPD foram também submetidos à análise de variância e as médias novamente comparadas pelo teste de Duncan a $5 \%$ de probabilidade.

Nos dois ensaios, os dados relativos à população residente da bactéria (PRB), expressos em log ufc/cm ${ }^{2}$, e aqueles relativos à severidade, correspondentes a cada um dos cinco tratamentos, foram submetidos à análise de correlação, considerando diferentes intervalos entre as respectivas avaliações. A análise de correlação também foi empregada com respeito aos dados calculados de AACPPR e AACPD. Em ambos os casos, consideraram-se apenas os valores de " $r$ " maiores que 0,50 ou menores que $-0,50$, significativos até $5 \%$ de probabilidade.

Efetuou-se, ainda, análise de correlação entre os valores relativos à população residente da bactéria (PRB) e de severidade com os dados de temperatura máxima e mínima $\left({ }^{\circ} \mathrm{C}\right)$, umidade relativa (\%) e precipitação pluviométrica (mm), registrados em estação meteorológica situada a cerca de 1000 $m$ das áreas experimentais. Nesta análise, foram consideradas quatro situações: a média entre as variáveis meteorológicas registradas três e sete dias antes da aferição da PRB e da severidade, no dia imediatamente anterior e no mesmo dia dessa aferição. Utilizou-se o mesmo critério quanto aos valores de " $\mathrm{r}$ " a considerar.

\section{RESULTADOS E DISCUSSÃO}

Constatou-se, 16 dias após as inoculações, alta população residente da bactéria, de $10^{3}$ a $10^{7} \mathrm{ufc} / \mathrm{cm}^{2}$ de folha, em ambos os ensaios (Figuras 1 e 2). Houve redução acentuada nesta população em seguida às três primeiras pulverizações, no ensaio com o isolado sensível ao cobre (ENA-818), quando registraram-se valores próximos de zero, principalmente nos tratamentos com sulfato de cobre, óxido cuproso e óxido cuproso+mancozeb. A partir da quarta avaliação, no entanto, os níveis da população residente voltaram àqueles registrados no início das avaliações, em todos os tratamentos, exceto nas parcelas pulverizadas com óxido cuproso, onde variaram entre 10 e $10^{2} \mathrm{ufc} / \mathrm{cm}^{2}$ e naquelas tratadas com óxido 
cuproso+mancozeb, caracterizadas por constantes oscilações (Figura 1). Esses resultados podem ser atribuídas à redução na concentração dos produtos nas folhas entre as pulverizações devido à lavagem pelas chuvas e irrigações a exemplo do observado por Carmo et al. (2001). No ensaio com o isolado resistente ao cobre (ENA-4369), a população residente situou-se sempre na ordem de $10^{4}$ a $10^{7}$ $\mathrm{ufc} / \mathrm{cm}^{2}$, em todos os tratamentos, exceto óxido cuproso+mancozeb onde observaram-se oscilações na população entre 0 e $10^{4} \mathrm{ufc} / \mathrm{cm}^{2}$ (Figura 2), analogamente ao observado no ensaio com o isolado sensível ao cobre. Este aumento na população neste tratamento nos dois ensaios pode, em parte, estar associado à disseminação da bactéria a partir daquelas parcelas com alta população residente.

Considerando todo o período de monitoramento da população residente do patógeno, expresso pelos valores da AACPPR, pode-se constatar que todos os tratamentos promoveram redução significativa desta no ensaio com o isolado sensível ao cobre, com maior destaque para os tratamentos com óxido cuproso e com óxido cuproso+mancozeb (Tabela 1). Para o isolado resistente, todavia, somente esses dois tratamentos diferiram da testemunha; já os tratamentos com sulfato e com oxicloreto de cobre, apesar de estatisticamente equivalentes ao óxido cuproso, não diferiram da testemunha (Tabela 1), concordando com os resultados de Jones et al. (1991) e Akiba et al. (1983). A população residente do isolado resistente ao cobre (ENA-4369) foi sempre superior a do isolado sensível (ENA-818), em todos os tratamentos (Tabela 1).

No entanto, embora os tratamentos com óxido cuproso e óxido cuproso+mancozeb tenham reduzido significativamente a população residente do isolado ENA-4369, isso não resultou em redução das infecções e assim da severidade da doença (Tabela 2). Por conseguinte, a resistência ao cobre desse isolado foi evidenciada no campo pela ineficiência dos compostos químicos em termos de reduzir a população residente a níveis suficientes para reduzir a severidade. Ainda, não houve dife-

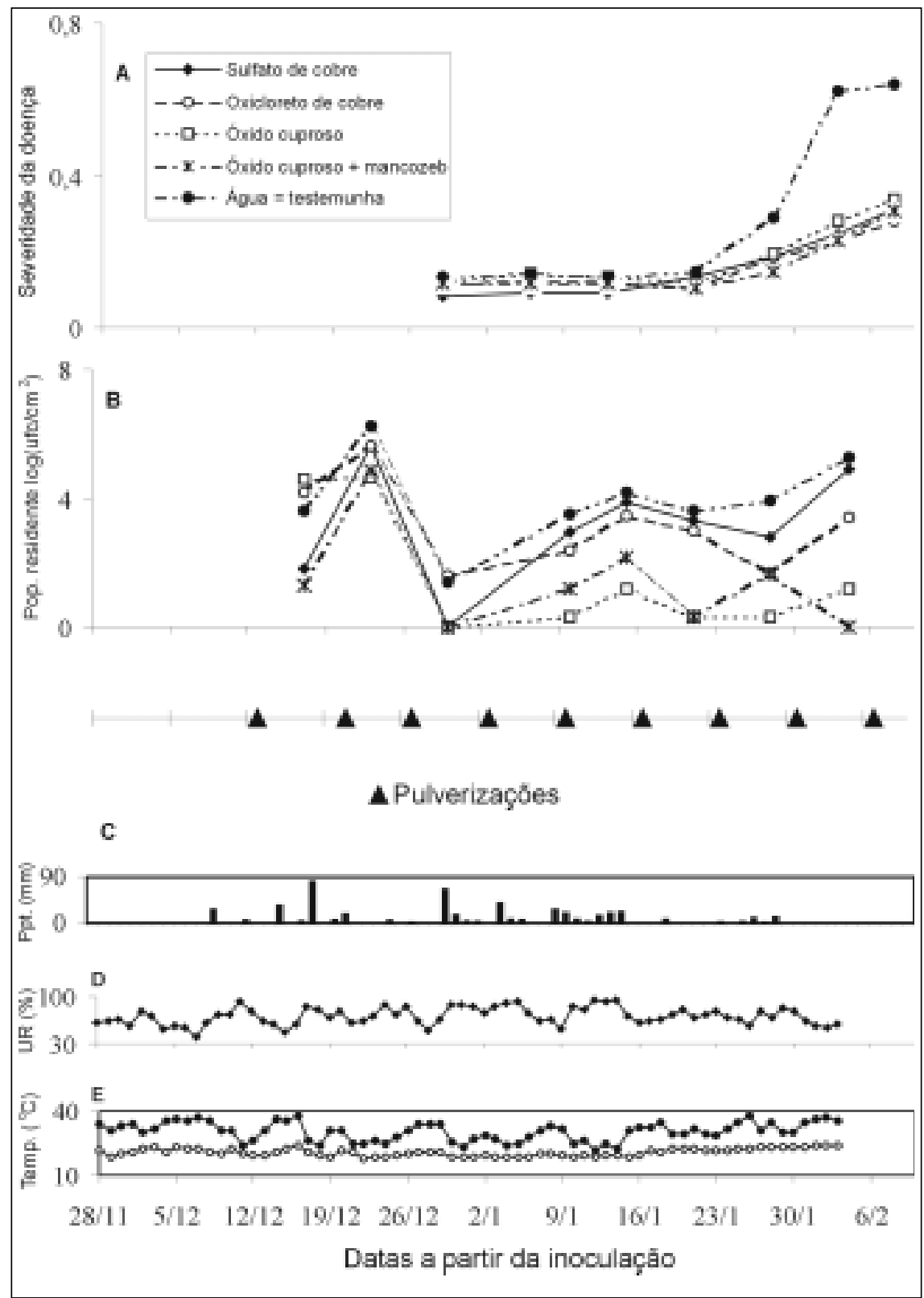

Figura 1. Evolução da mancha-bacteriana do pimentão, em parcelas experimentais tratadas com diferentes produtos químicos, expressa pela proporção da área foliar lesionada (severidade) (A) e pelo nível da população residente de Xanthomonas campestris pv. vesicatoria (B), em enasio com isolado sensível ao cobre (ENA-818) realizado sob as condições climáticas indicadas, precipitação (C), umidade relativa (D) e temperatura (E). Seropédica, UFRuralRJ, 1993-1994.

rença significativa entre o tratamento óxido cuproso+mancozeb e óxido cuproso para nenhuma das duas variáveis avaliadas, população residente da bactéria (PRB) e severidade da doença, em ambos os ensaios (Tabela 1 e 2). $\mathrm{O}$ mancozeb não possui $\mathrm{Cu}^{++}$em sua composição básica, porém, ao ser misturado com fungicidas cúpricos promove uma redução do pH da solução e, conseqüentemente, aumento da solubilida- de do cobre e de sua concentração na solução (Adaskaveg \& Hine, 1985; Marco \& Stall, 1983). Sendo assim, o aumento de sua eficiência poderá variar com o grau de sensibilidade do isolado bacteriano ao cobre. Maringoni \& Kimati (1987) relatam efeito bactericida do uso isolado do mancozeb, in vitro, e efeito sinergístico pelo uso das misturas cuprorgânicas apenas para alguns isolados de $X c v$. 
Tabela 1. Efeitos de formulações cúpricas e cuprorgânicas nos níveis populacionais de isolados de Xanthomonas campestris pv. vesicatoria, resistente (ENA-4369) ou sensível (ENA-818) ao cobre in vitro, residentes no filoplano de plantas de pimentão. Seropédica, UFRRJ, $1993-1994$.

\begin{tabular}{lcccc}
\hline \multicolumn{1}{c}{ Tratamento } & $\begin{array}{c}\text { Concentração de } \\
\text { Cu++ }(\mu \mathbf{g} / \mathbf{m l})\end{array}$ & ENA-818 & EACPPR-4369 \\
\cline { 3 - 5 } & 0,0 & $183,112 \mathrm{a}$ & $234,40 \mathrm{a}$ \\
Água bidestilada/deionizada & 112,5 & $147,74 \quad \mathrm{~b}$ & $200,07 \mathrm{ab}$ \\
Sulfato de cobre & 42,6 & $144,89 \mathrm{~b}$ & $196,34 \mathrm{ab}$ \\
Oxicloreto de cobre & 20,2 & 64,45 & $\mathrm{C}$ & $165,10 \mathrm{bc}$ \\
Óxido cuproso & 22,2 & $74,60 \quad \mathrm{C}$ & $131,93 \quad \mathrm{c}$ \\
Óxido cuproso + mancozeb & & 12,70 & 16,99
\end{tabular}

${ }^{1}$ AACPPR = Área Abaixo da Curva de Progresso da População Residente, expressa em log ufc/ $/ \mathrm{cm}^{2} ;{ }^{2}$ os valores representam médias de três repetições; médias seguidas de letras iguais, nas colunas, não diferem entre si pelo teste de Duncan a 5\% de probabilidade.

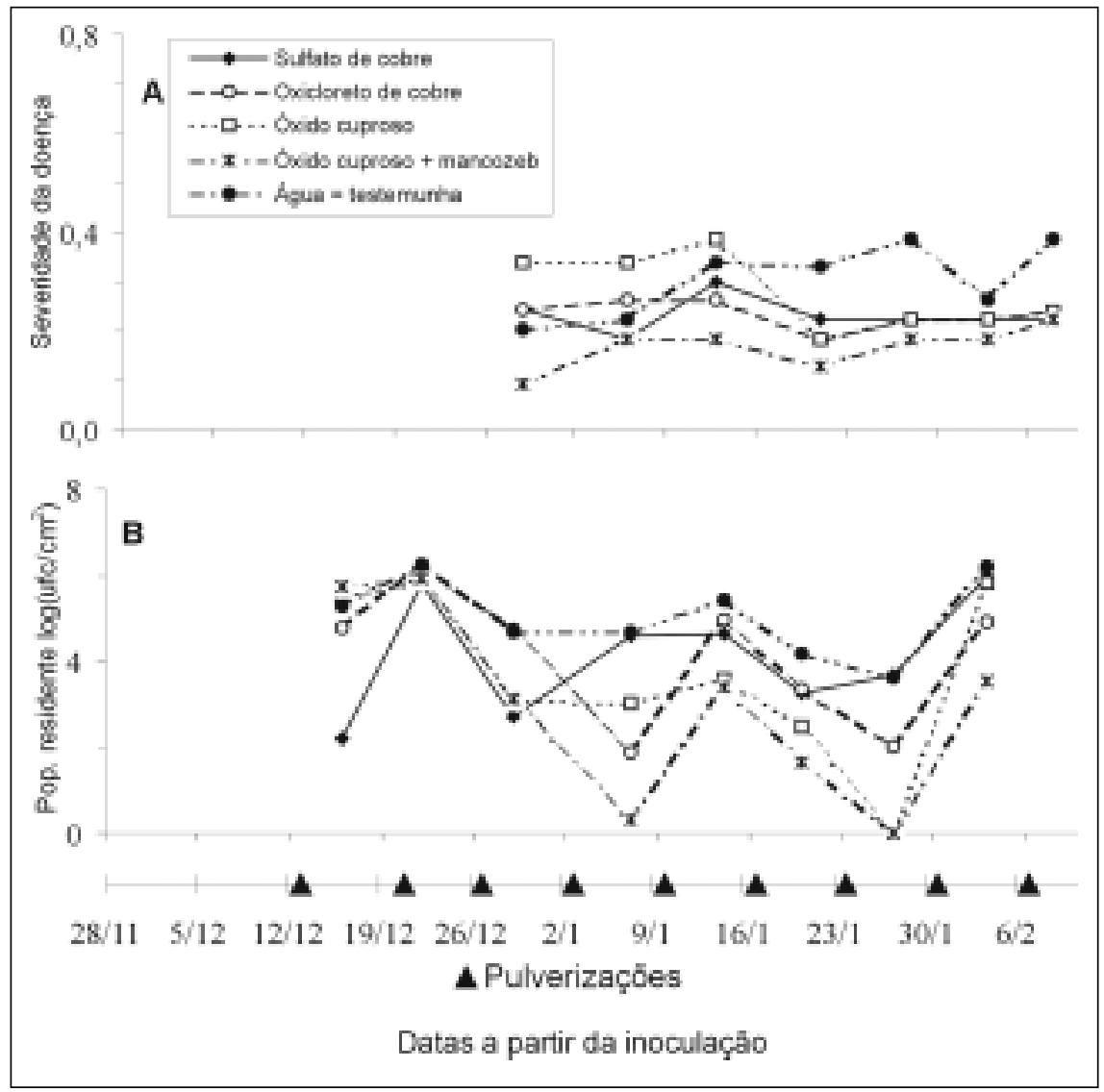

Figura 2. Evolução da mancha-bacteriana do pimentão, em parcelas experimentais tratadas com diferentes produtos químicos, expressa pela proporção da área foliar lesionada (severidade) (A) e pelo nível da população residente de Xanthomonas campestris pv. vesicatoria (B), em ensaio com isolado resistente ao cobre (ENA-4369). Seropédica, UFRuralRJ, 1993-1994.

Resultados análogos aos deste trabalho foram reportados por Silva \& Lopes (1995), que não obtiveram controle químico efetivo de uma estirpe de Pseudomonas syringae pv. tomato resistente ao cobre afetando o tomateiro. Goto et al. (1993) relataram que uma concentração de $174 \mathrm{mg} / \mathrm{ml} \mathrm{de} \mathrm{Cu}^{++}$era na epidemiologia da doença (Carmo et al., 1996). Por outro lado, chuvas freqüentes e irrigações por aspersão contribuem para a lavagem de resíduos dos produtos, reduzindo sua concentração, simultaneamente ao estabelecimento de condições propícias à infecção (Carmo et al., 2001).

No ensaio com o isolado sensível ao cobre (ENA-818), a comparação entre as médias correspondentes à AACPD revelou que todas as formulações químicas testadas tiveram efeito significativo na redução da severidade da doença, diferindo da testemunha não tratada. Já no ensaio com o isolado resistente (ENA-4565), nenhum tratamento diferiu da testemunha, concordando com os resultados de Marco \& Stall (1983).

De forma geral, pode-se afirmar que as diferenças constatadas entre os tratamentos, quanto à redução da população residente de $X c v$, não corresponderam a diferenças quanto à diminuição das infecções, confirmadas pela análise de correlação entre os valores de AACPPR e de AACPD, a qual indicou coeficientes " $r$ " significativos, porém baixos, 0,47 e 0,55, para os isolados sensível e resistente ao cobre, respectivamente.

Esta baixa correlação entre os resultados da avaliação da população residente da bactéria e a severidade da doença, principalmente no ensaio com o isolado resistente, foi confirmada após análises de correlação mais detalhadas. Obtiveram-se coeficientes de correlação "r" significativos e positivos entre a população residente da bactéria sensível ao cobre (ENA-818) e a severidade da doença somente quando as avaliações 
Tabela 2. Efeitos de formulações cúpricas e cuprorgânicas no progresso da mancha-bacteriana do pimentão (cv. Cascadura Itaipu) após inoculação com isolados de Xanthomonas campestris pv. vesicatoria resistente (ENA-4369) ou sensível (ENA-818) ao cobre in vitro. Seropédica, UFRRJ, 1993-1994.

\begin{tabular}{lcrrr}
\hline \multirow{2}{*}{ Tratamento } & Concentração de & \multicolumn{4}{c}{ AACPD $^{1}$} \\
\cline { 3 - 5 } & Cu++ ( mg/ml) & \multicolumn{2}{c}{ ENA-818 } & ENA-4369 \\
\hline Água bidestilada/deionizada & 0,0 & 1062,6 & $\mathrm{a}^{2}$ & $1244,5 \mathrm{a}$ \\
Sulfato de cobre & 112,5 & 602,7 & $\mathrm{~b}$ & $1258,8 \mathrm{a}$ \\
Oxicloreto de cobre & 42,6 & 625,2 & $\mathrm{~b}$ & $1026,3 \mathrm{a}$ \\
Óxido cuproso & 20,2 & 706,2 & $\mathrm{~b}$ & $828,0 \mathrm{a}$ \\
Óxido cuproso + mancozeb & 22,2 & 600,9 & $\mathrm{~b}$ & $949,5 \mathrm{a}$ \\
\hline C. V. (\%) & & 17,8 & 22,6 \\
\hline
\end{tabular}

${ }^{1} \mathrm{AACPD}=$ Área Abaixo da Curva de Progresso da Doença;

${ }^{2}$ os valores representam médias de três repetições; médias seguidas de letras iguais, nas colunas, não diferem entre si pelo teste de Duncan a $5 \%$ de probabilidade.

foram efetuadas no mesmo dia ou no máximo com um dia de diferença para os tratamentos sulfato de cobre $(0,63)$, oxicloreto de cobre $(0,66)$, óxido cuproso $(0,71)$ e testemunha $(0,76)$ ou entre a população residente e a severidade registrada nos sete dias anteriores para os tratamentos sulfato de cobre $(0,69)$, óxido cuproso $(0,93)$ e testemunha $(0,93)$, enquanto que para o tratamento óxido cuproso+mancozeb obteve-se coeficiente significativo, porém negativo $(-0,73)$. No caso do isolado resistente (ENA-4369), por seu turno, constataram-se coeficientes de correlação significativos e positivos entre população residente e a severidade, apenas nas avaliações registradas sete dias após a quantificação das bactérias presentes no filoplano, para os tratamentos oxicloreto de cobre $(0,68)$ e óxido cuproso + mancozeb $(0,79)$, ou 12 a 14 dias antes da quantificação da severidade para o tratamento sulfato de cobre (0,70). Essa menor frequiência de correlações significativas, provavelmente deveu-se ao estágio mais avançado da epidemia e à pouca variação na severidade, semelhante ao observado em curvas de progresso da doença por outros autores. No ensaio com o isolado ENA818 as primeiras avaliações coincidiram com a fase inicial de desenvolvimento lento da epidemia.

Os resultados acima comentados evidenciaram que a percentagem de área foliar lesionada é um indicador mais adequado para monitorar o inóculo secundário e, conseqüentemente, para estimar futuras taxas de infecção, do que o nível da população residente do patógeno, provavelmente por ser esta última variável mais instável, respondendo muito rapidamente a variações de temperatura/umidade e a produtos químicos aplicados. Em contrapartida, as células da bactéria presentes no interior dos tecidos da planta estão menos sujeitas a tais variações climáticas e mais protegidas da ação dos químicos.

Os níveis da população residente e as variações na severidade da doença não se correlacionaram de forma consistente com nenhuma das variáveis meteorológicas analisadas: temperaturas máxima e mínima, umidade relativa do ar e precipitação pluviométrica, registradas em datas anteriores à aferição da PRB e de quantificação da severidade.

Tanto os níveis da PRB quanto de severidade da mancha-bacteriana foram mais intensos nas plantas de pimentão inoculadas com o isolado ENA-4369, indicando, assim, que haverá maior dificuldade de controle da doença com a predominância de populações de $X c v$ portando genes para resistência ao cobre, especialmente se as pulverizações forem iniciadas após o estabelecimento da doença.

\section{LITERATURA CITADA}

ADASKAVEG, J.E.; HINE, R.B. Copper tolerance and zinc sensitivity of Mexican strains of Xanthomonas campestris pv. vesicatoria, casual agent of bacterial spot of pepper. Plant Disease, v. 69, p. 993-996, 1985.

AGUIAR, L.A.; KIMURA, O.; CASTILHO, A.M.C.; CASTILHO, K.S.C.; RIBEIRO, R.L.D.;
AKIBA, F.; CARMO, M.G.F. Resistência ao cobre em isolados nacionais de Xanthomonas campestris pv. vesicatoria de pimentão e tomateiro. Agronomia, Seropédica, v. 34, n. 1, p. 78-82, 2000.

AKIBA, F.; ROSSI, R.F.; ROBBS, C.F.; ALMEIDA, O.C. Comparação de produtos químicos no controle da pústula bacteriana do pimentão causada por Xanthomonas campestris pv. vesicatoria. Fitopatologia Brasileira, Brasília, v. 8, p. 630, 1983. (Resumo).

BASHAN, Y.; OKON, Y.; HENIS, Y. Long-term survival of Pseudomonas syringae pv. tomato and Xanthomonas campestris $p v$. vesicatoria in tomato and pepper seeds. Phytopathology, v. 72, p. 11431144, 1982.

CARMO, M.G.F.; MAFFIA, L.A.; KIMURA, O.; CARVALHO, A.O. Progresso da pústula bacteriana do pimentão, causada por Xanthomonas campestris pv. vesicatoria, em condições de viveiro. Fitopatologia Brasileira, Brasília, v. 21, p. 62-70, 1996.

CARMO, M.G.F.; MACAGNAN, D.; CARVALHO, A.O. Progresso da mancha-bacteriana do pimentão a partir de diferentes níveis iniciais de inóculo e do emprego ou não do controle com oxicloreto de cobre. Horticultura Brasileira, Brasília, v. 19, n. 3, p. 342-347, 2001.

CANTEROS, B.I.; MINSAVAGE, G.V.; PRING, D.R.; STALL, R.E. Plasmid-encoded copper resistance in Xanthomonas campestris pv. vesicatoria. In: Proc. 7th Int. Conf. Plant Pathogenic Bacteria, 1990. (Abstract).

GITAITIS, R.D.; McINNES, T.B.; JONES, J.B. A survey of Georgia and Florida for the presence of copper tolerant phytopathogenic bacteria. Phytopathology, v. 75, p. 1288, 1985. (Abstract). GOTO, M.; HIKOTA, T.; KYUDA, T.; NAKAJIMA, M. Induction of copper resistance in plant-pathogenic bacteria exposed to glutamate, plant extracts, phosphate buffer, and some antibiotics. Phytopathology, v. 83, p. 1449-1453, 1993.

HIRANO, S.S.; UPPER, C.D. Population biology and epidemiology of Pseudomonas syringae. Annual Review of Phytopatholology, v. 28, p. 155-177, 1990. HORSFALL, J.G.; BARRAT, R.W. An improved grading system for measuring plant diseases. Phytopathology, v. 35, p. 365, 1945. (Abstract).

JONES, J.B.; WOLTZ, S.S.; JONES, J.P.; PORTIER, K.L. Population dynamics of Xanthomonas campestris pv. vesicatoria on tomato leaflets treated with copper bactericides. Phytopathology, v. 81, p. 714-719, 1991. 


\section{A. Aguiar et al.}

JONES, J.B.; STALL, R.E.; BOUZAR, H. Diversity among xanthomonads pathogenic on pepper and tomato. Annual Review of Phytopathology, v. 36, p. 41-58, 1998.

KIMURA, O. Enfermidades bacterianas do pimentão. Informe Agropecuário, Belo Horizonte, v. 10, p. 39-41, 1984.

KIMURA, O.; CARMO, M.G.F. Doenças causadas por bactérias em pimentão. Informe Agropecuário, Belo Horizonte, v. 18, p. 66-73, 1996.

KIMURA, O; RIBEIRO, R.L.D.; AKIBA; F.; BRIOSO, P.S.T. Populações residentes de Xanthomonas campestris $p v$. vesicatoria em folhas de germoplasma resistente e suscetível de pimentão (Capsicum annиum L.). Fitopatologia Brasileira, Brasília, v. 6, p. 545-546, 1981. (Resumo).
MARCO, G.M.; STALL, R.E. Control of bacterial spot of pepper initiated by strains of Xanthomonas campestris $p v$. vesicatoria that differ in sensitivity to copper. Plant Disease, v. 67, p. 779-781, 1983. MARINGONI, A.C.; KIMATI, H. Sensibilidade in vitro de Xanthomonas campestris pv. vesicatoria (Doidge) Dye de pimentão e de tomateiro a drogas. Summa Phytopathologica, São Paulo, v. 13, p. 160-172, 1987.

McCARTER, S.M. Effects of bactericide treatments on bacterial spot severity and yield of different pepper genotypes and on populations of certain insects. Plant Disease, v. 76, p. 1042-1045, 1992.
RODRIGUES NETO, J.; MALAVOLTA JR., V.A.; VICTOR, O. Meio simples para isolamento e cultivo de Xanthomonas campestris pv. citri tipo B. Summa Phytopathologica, São Paulo, v. 12, n. 1-2, p. 16, 1986. (Resumo).

SILVA, V.L.; LOPES, C.A. Isolados de Pseudomonas syringae pv. tomato resistentes a cobre em tomateiros pulverizados com fungicidas cúpricos. Fitopatologia Brasileira, Brasília, v. 20, p. 85-89, 1995.

STALL, R.E. Xanthomonas campestris pv. vesicatoria: cause of bacterial spot of tomato and pepper. In: SWINGS, J.G.; CIVEROLO, E.L. (Eds.). Xanthomonas. CHAPMAN \& HALL, London, p. 57-60, 1993. 